\title{
BLICKDIAGNOSE
}

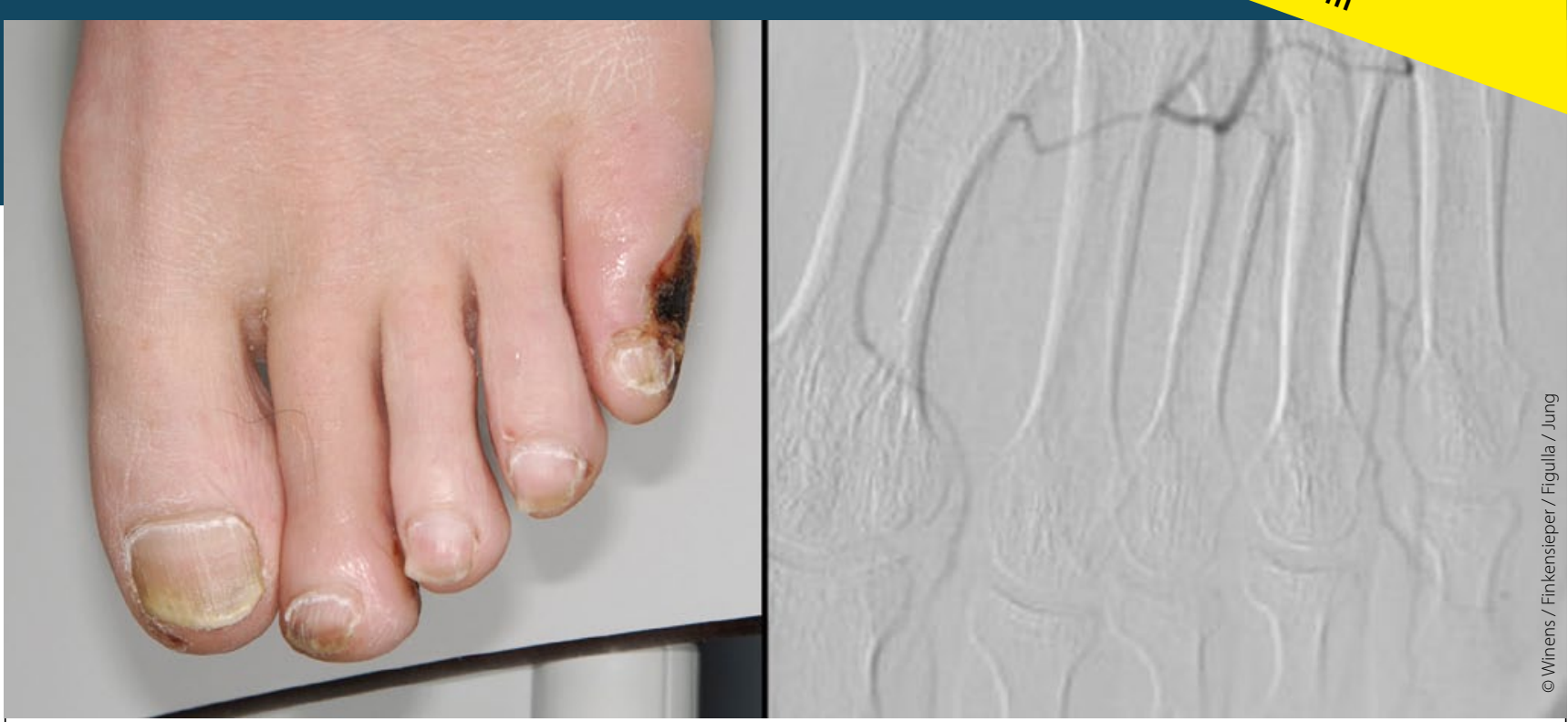

"Schlecht heilende schwarze Stellen"

\section{Was steckt hinter diesen Fußulzera?}

Die Ätiologie von Fußulzera kann sehr verschieden sein. Neben den häufigen Ursachen wie venöse Druckerhöhung, Diabetes mellitus und periphere arterielle Verschlusskrankheit (PAVK), die zusammen für über $90 \%$ [1] der chronischen Läsionen verantwortlich sind, spielen auch seltene Ursachen wie kardiale Embolien oder Vaskulitiden eine Rolle.

— Ein 40-jähriger Patient wurde aufgrund einer dilatativen Kardiomyopathie mit hochgradig eingeschränkter linksventrikulärer Ejektionsfraktion in unsere Klinik überwiesen. Eine kardiale Dekompensation war bereits therapiert worden. Der Patient gab eine mäßige Belastungsdyspnoe an. Auf Nachfrage berichtet er von einem chronischer Nikotinabusus (20 Packungsjahre). Nur beiläufig erwähnt er, dass er seit etwa vier Wochen an der 1., 2. und 5. Zehe des linken Fußes "schlecht heilende schwarze Stellen" habe (siehe Abb. links). In der klinischen Untersuchung präsentierten sich die „schwarzen Stellen" als trockene Nekrosen ohne lokale Entzündungszeichen.

Bei der Suche nach der Ursache der Nekrosen richtete sich der Fokus zunächst auf die vordergründig bestehende Herzinsuffizienz, die mit einer mittel- bis hochgradigen Aortenklappeninsuffizienz verbunden war. Unter dem Verdacht einer (stattgehabten) Endokarditis mit konsekutiver Freisetzung thrombotischen Materials wurde eine transösophageale Echokardiografie durchgeführt, die eine am ehesten postendokarditisch destruierte Klappe zeigte, allerdings keinen Nachweis von thrombotischen Auflagerungen an den Klappen. Eine normwertige Dopplerdruck- sowie Duplexmessung der Beinarterien schloss eine pAVK aus. Eine weitere Ursache der Nekrosen hätte in einer Vaskulitis liegen können, die entsprechenden laborchemischen Untersuchungen waren jedoch negativ.

Die Angiografie der Beinarterien stellte unauffällige große Arterien dar, allerdings eine deutlich rarifizierte Endstrombahn (Abb. rechts). Unter dem Verdacht auf eine Thrombangiitis obliterans wurde dem Patienten dringend eine Nikotinkarenz angeraten und eine intravenöse Therapie mit Prostavasin durchgeführt.

Keywords: Winiwarter-Buerger disease

1. Mekkes JR, Loots MA, Van Der Wal AC, Bos JD. Causes, investigation and treatment of leg ulceration. Br J Dermatol 2003; 3: 388-401

- Thomas Winkens, Dr. med. Andreas Finkensieper, Prof. Dr. med. HansR. Figulla, Dr. med. Christian Jung Klinik für Innere Medizin I der Universitätsklinik Jena, Erlanger Allee 101, D-07747 Jena 